\title{
Magnetophoresis of Magnetic Pickering Emulsion Under Low Field Gradient: Macroscopic and Microscopic Motion
}

Foo Kean Tham, ${ }^{1}$ Wei Ming Ng, ${ }^{1}$ Sim Siong Leong, ${ }^{1,2}$ Swee Pin Yeap, ${ }^{1,3}$ Siew Chun Low, ${ }^{1}$ Hooi Ling Lee,${ }^{4}$ JitKang Lim ${ }^{1,5 *}$

${ }^{1}$ School of Chemical Engineering, Universiti Sains Malaysia, 14300 Nibong Tebal, Penang, Malaysia.

${ }^{2}$ Department of PetroChemical Engineering, Faculty of Engineering and Green Technology, Universiti Tunku Abdul Rahman, 31900, Kampar, Perak, Malaysia.

${ }^{3}$ Faculty of Engineering, Technology and Built Environment, UCSI University Kuala Lumpur, Malaysia

${ }^{4}$ Nanomaterials Research Group, School of Chemical Sciences, Universiti Sains Malaysia, 11800 USM, Penang, Malaysia.

${ }^{5}$ Department of Physics, Carnegie Mellon University, Pittsburgh, PA 15213, USA.

*Corresponding author.Email: chjitkangl@usm.my

\section{List of figure and table}

Magnetic field and field gradient of the cylindrical magnet used (Figure S1); Magnetic field and field gradient of the bar magnet used (Figure S2); FTIR spectrum for PSS, CTAB and Dodecane (Figure S3); Microscopic images of MPE at various pH (Figure S4); TGA curve for all IONPs used at different stages (Figure S5); Time lapse images of MPE undergoing creaming process (Figure S6); Calculation steps involved in getting results shown in Table 1 of the manuscript. 


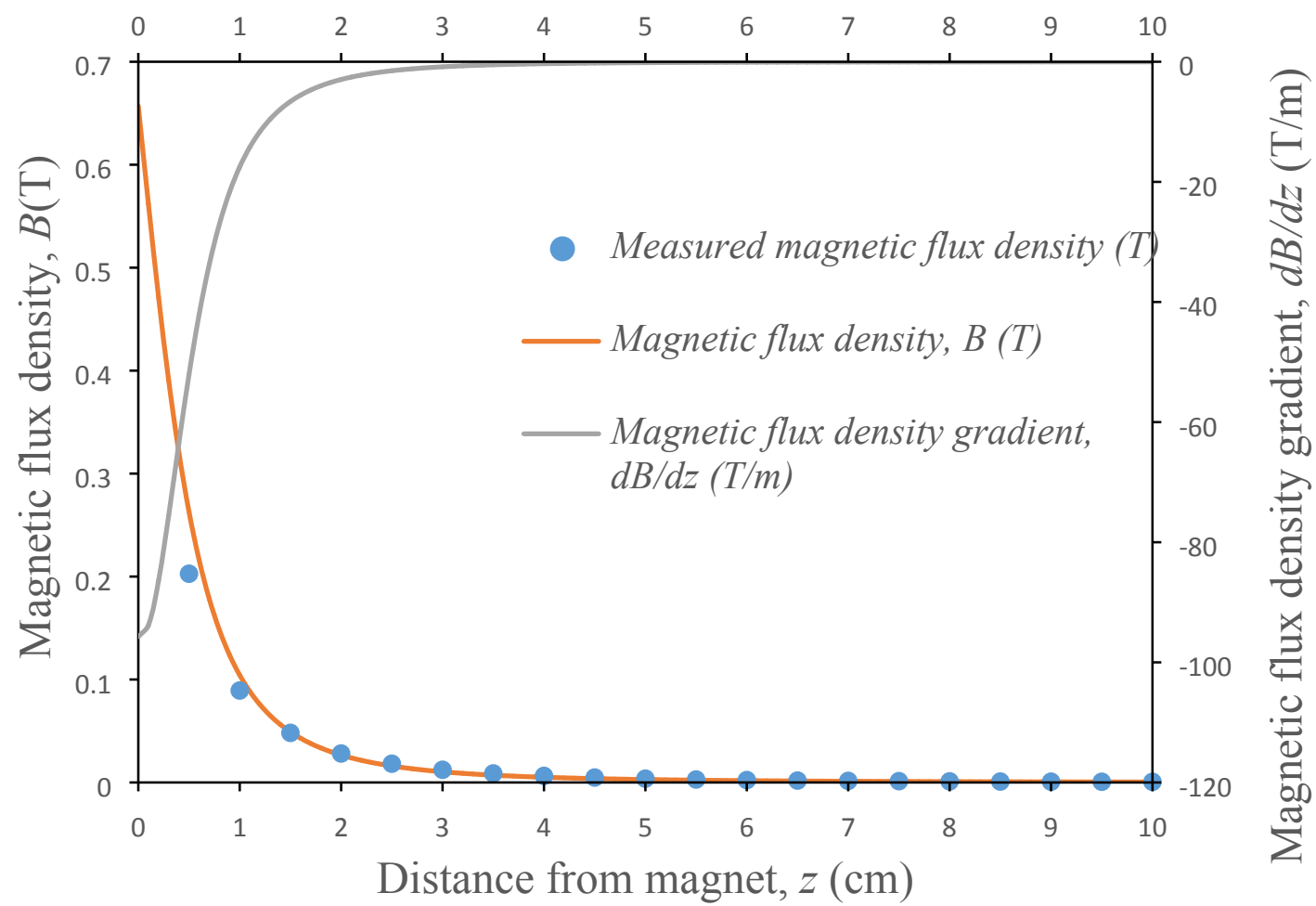

Figure S1. Magnetic field, $B$ and magnetic field gradient, $d B / d z$ profile of the cylindrical magnet used in macroscopic experiment. 
(a)

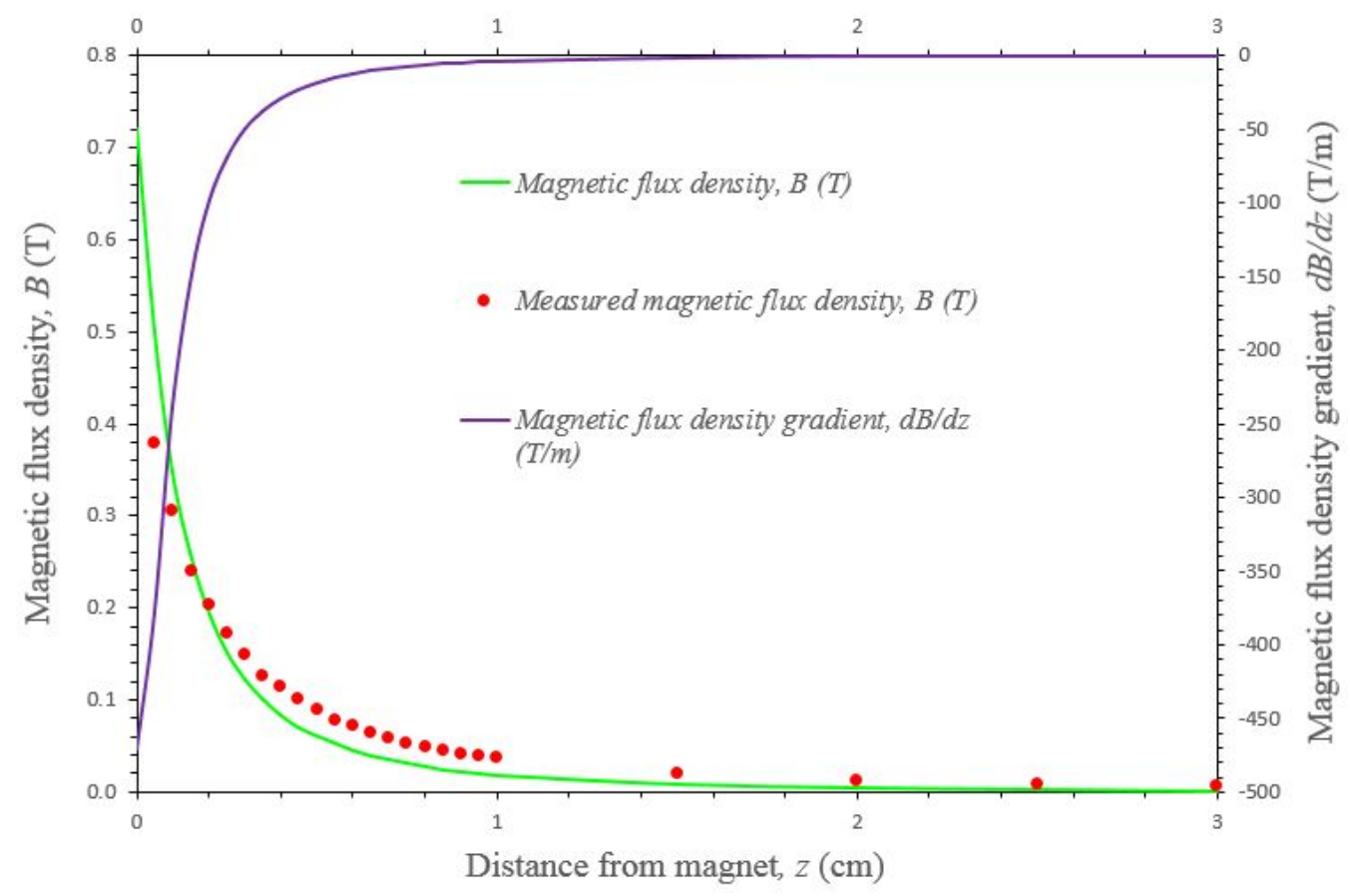

(b)

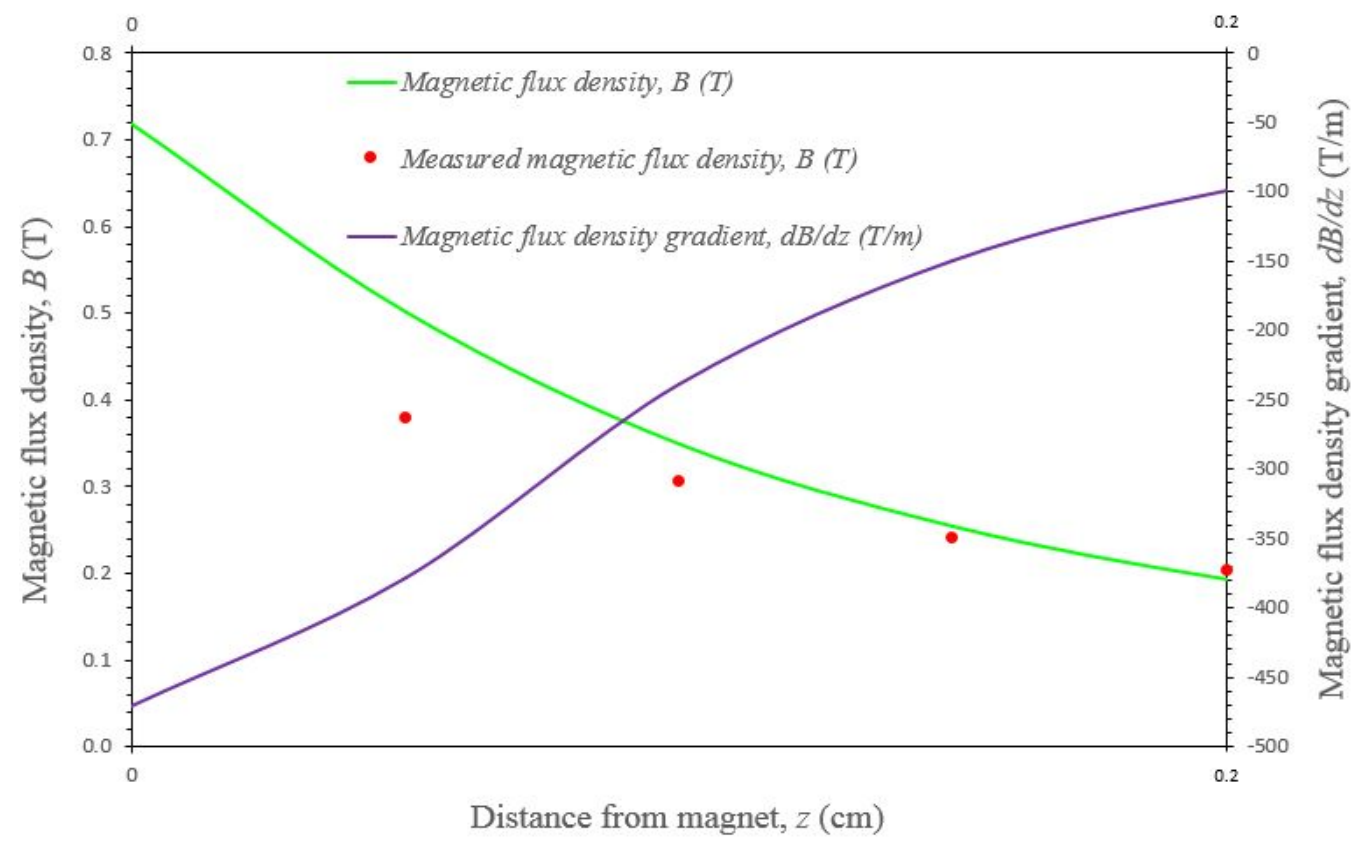

Figure S2 Magnetic field, $B$ and magnetic field gradient, $d B / d z$ profile of thin bar magnet for distance of (a) $0-3 \mathrm{~cm}$ (b) $0-0.2 \mathrm{~cm}$. 
(a)

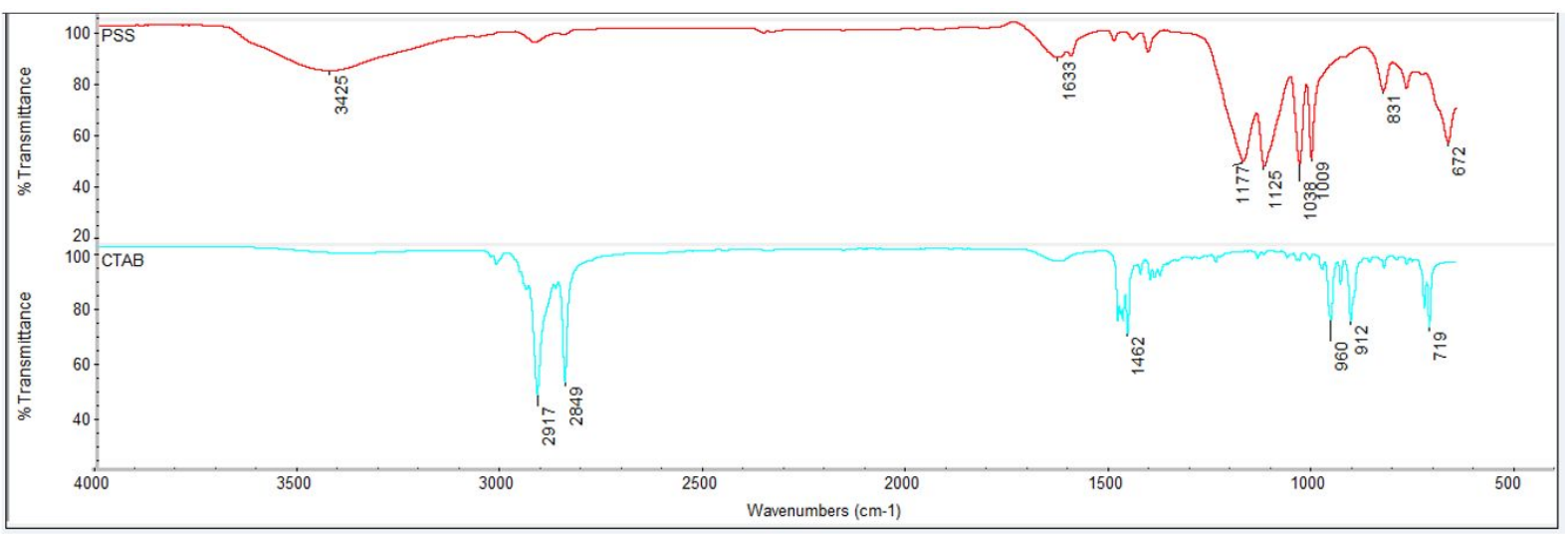

(b)

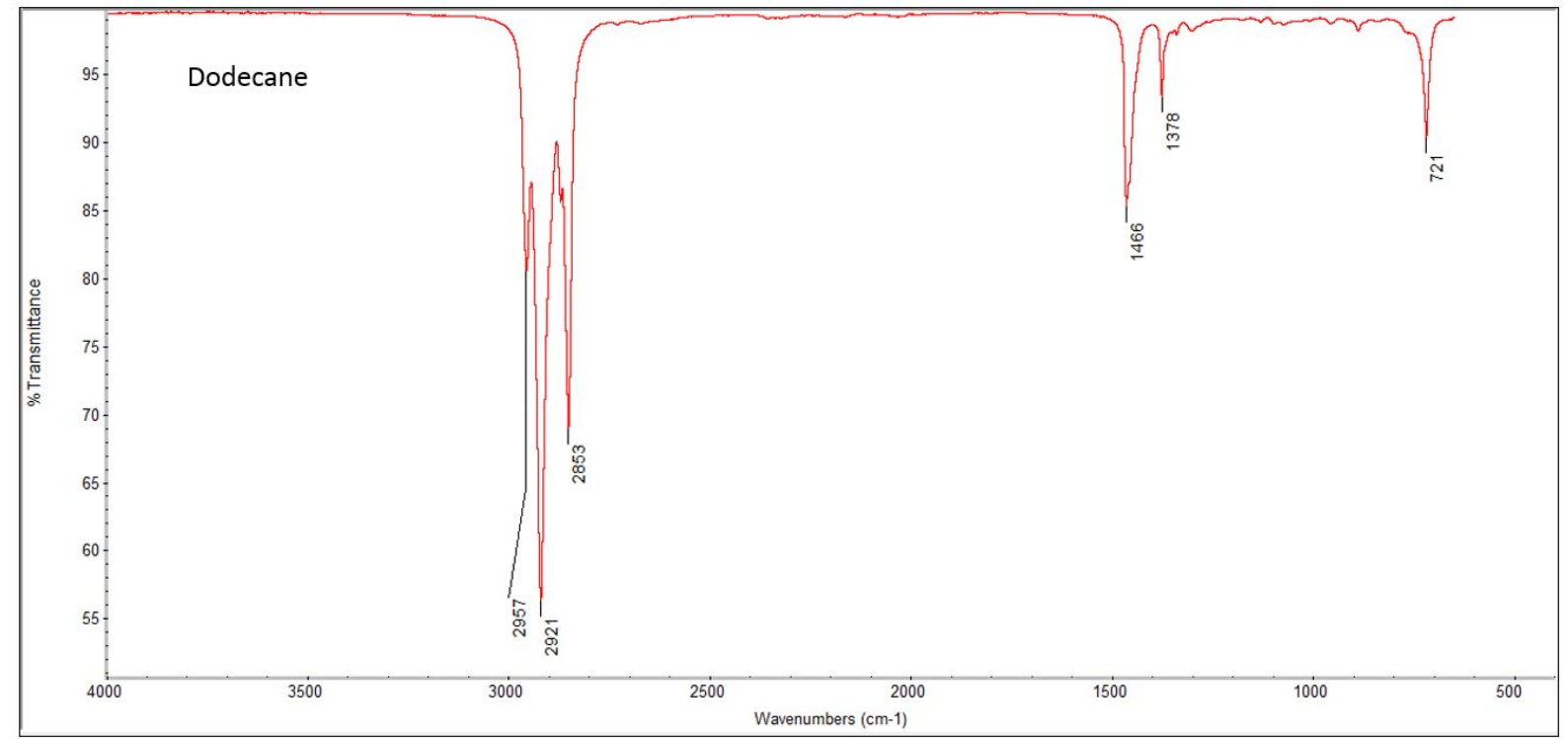

Figure S3 (a) FTIR spectrum of (top - red) Pure PSS molecule and (bottom - blue) Pure CTAB molecule. (b) FTIR spectrum of Dodecane 

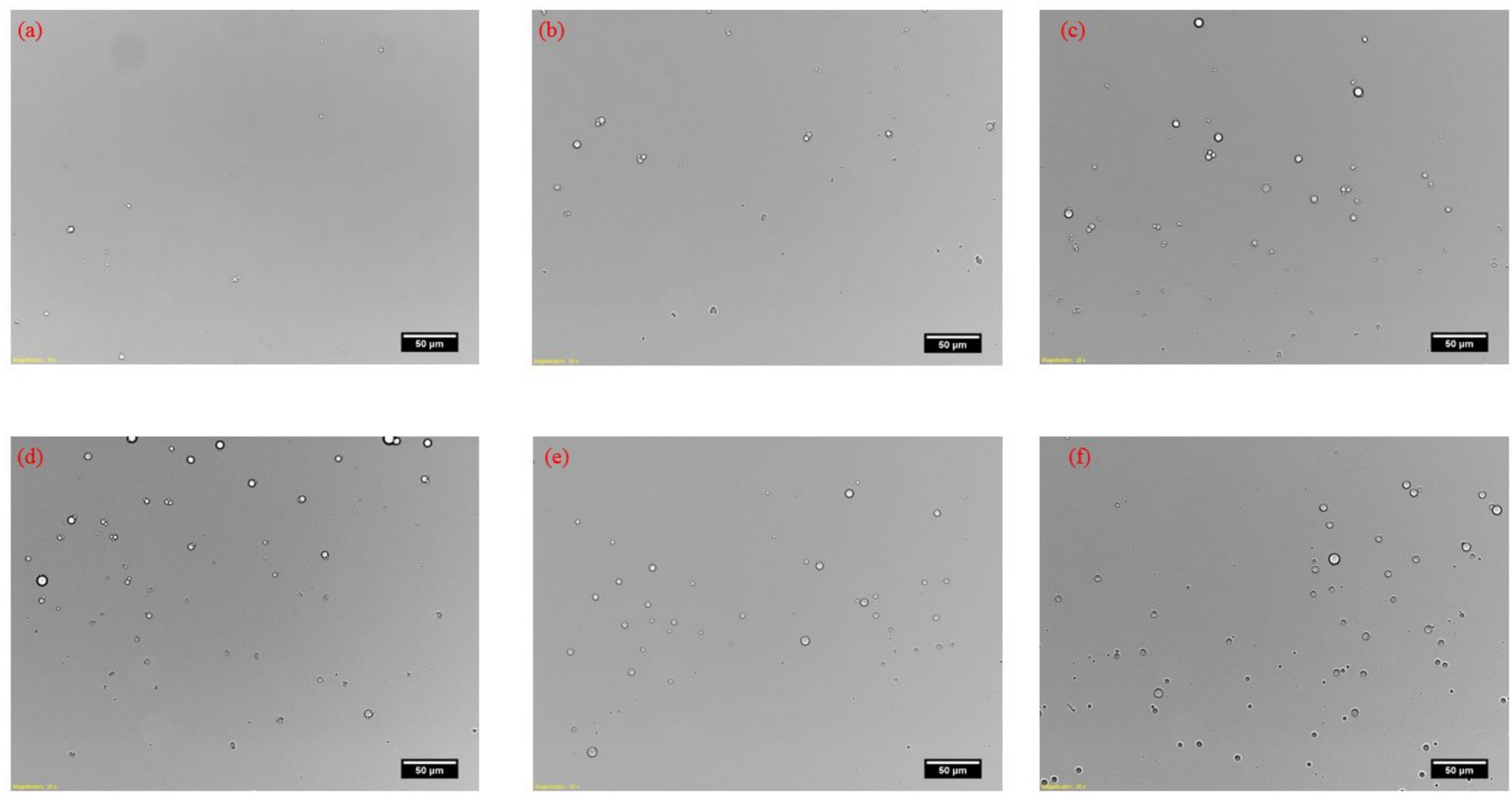

Figure S4. Microscopic images of MPE at (a) $\mathrm{pH} \mathrm{3,} \mathrm{(b)} \mathrm{pH}$ 4, (c) pH 6, (d) pH 7, (e) pH 8, (f) pH 10, (g) pH 11 and (h) deionized water. 

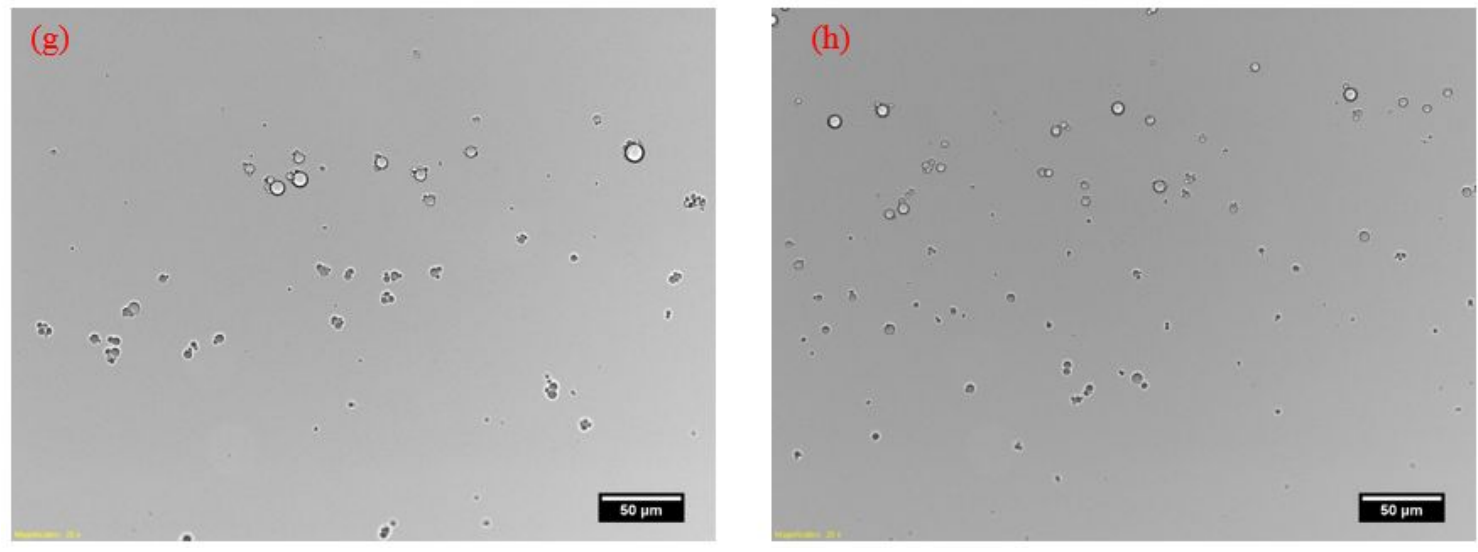

Figure S4. Continue 
(a)

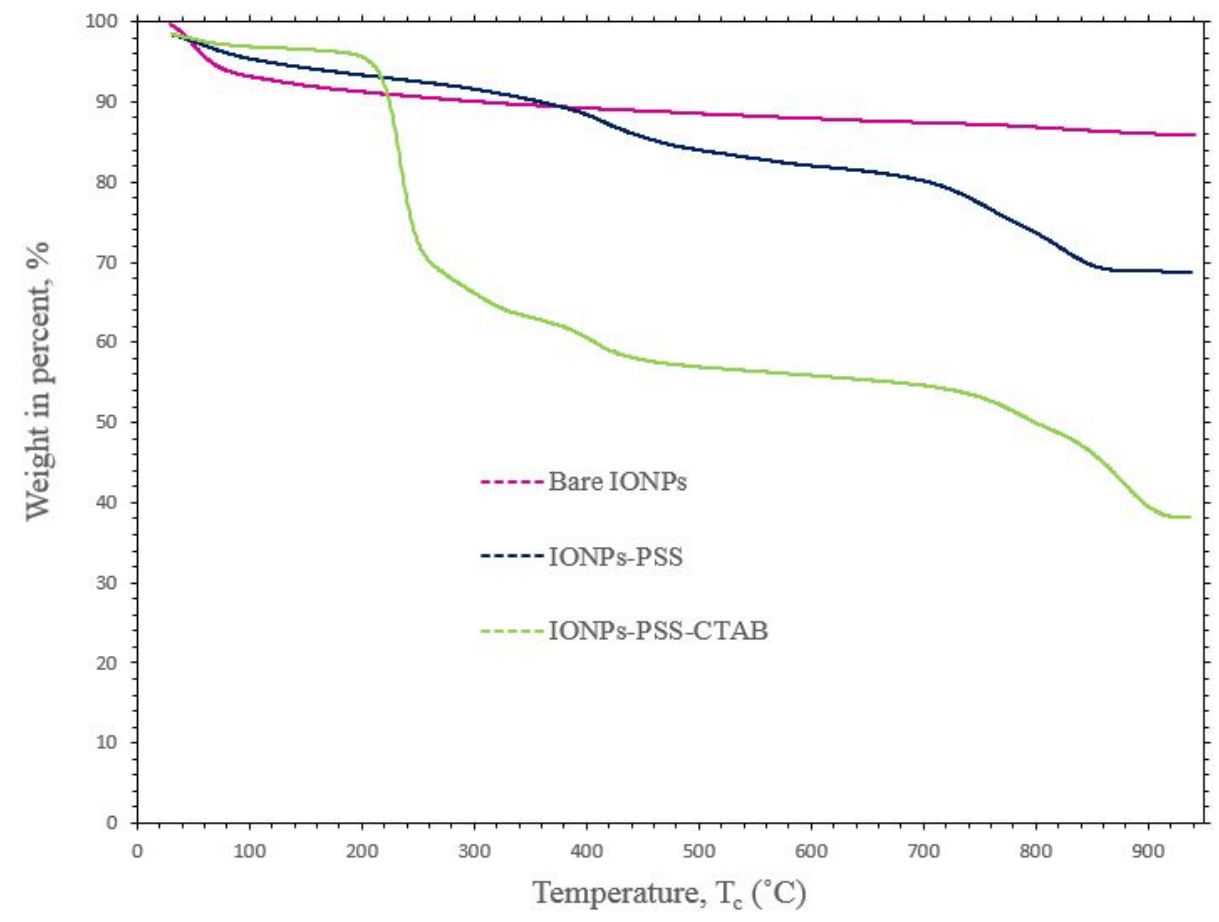

(b)

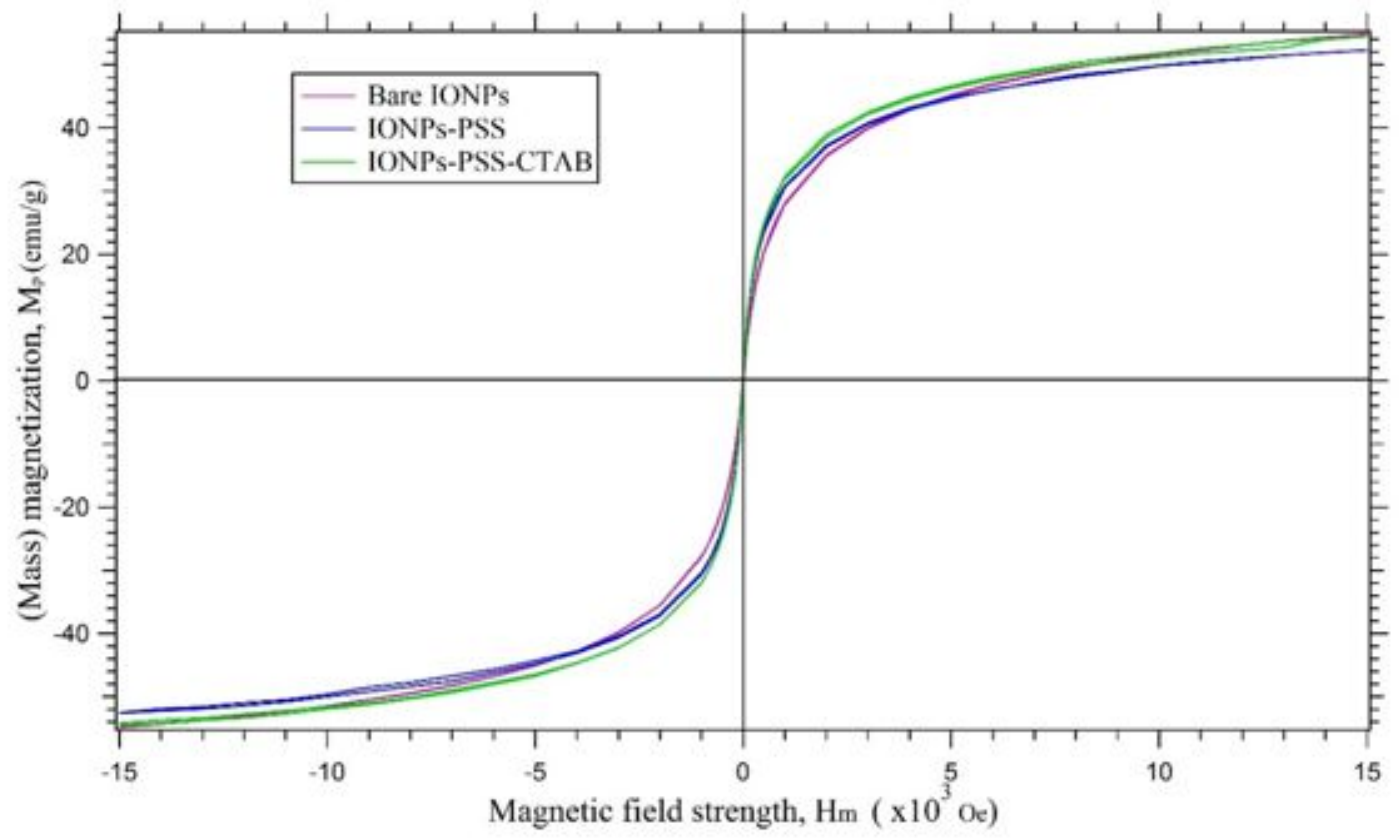

Figure S5. (a) TGA curve of bare IONPs, IONPs-PSS and IONPs-PSS-CTAB and (b) $M-H_{m}$ the curve of bare IONPs, IONPs-PSS and IONPs-PSS-CTAB. 
$0 \mathrm{~s} \quad 5 \mathrm{~min} \quad 10 \mathrm{~min} \quad 30 \mathrm{~min} \quad 60 \mathrm{~min} 90 \mathrm{~min} \quad 120 \mathrm{~min} \quad 150 \mathrm{~min} \quad 180 \mathrm{~min} 210 \mathrm{~min} 240 \mathrm{~min}$

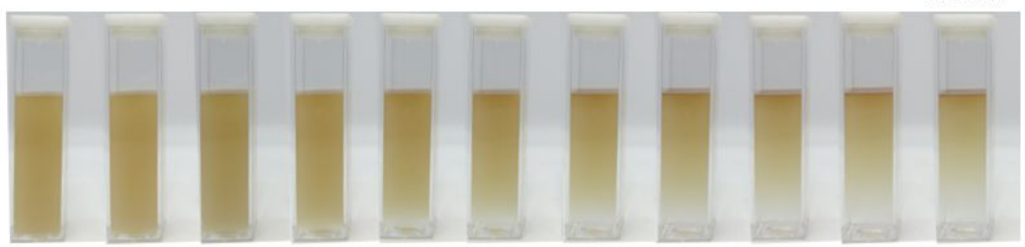

(a)

$\mathrm{pH} 3$

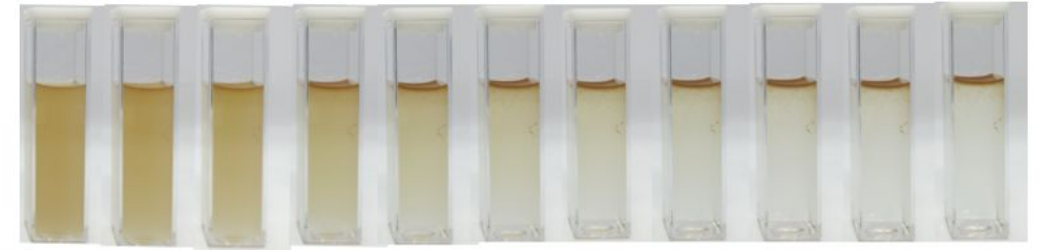

(b)

$\mathrm{pH} 10$

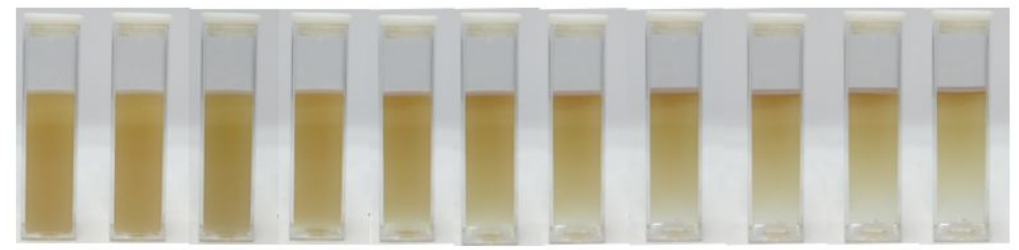

(c)

Deionized Water

Figure S6. Three series of time lapse images showing the turbidity changes of MPE over 4 hours due to the flocculation of MPE (creaming process). The MPE was dispersed in solution at (a) $\mathrm{pH}$ 3, (b) $\mathrm{pH} 10$ and (c) $\mathrm{pH} 7$ (deionized water). 
Calculation of number of IONP deposited on the emulsion droplet of MPE, packing density of IONPs and percentage of IONPs coverage

Six different diameters $(2.5 \mu \mathrm{m}, 3.5 \mu \mathrm{m}, 4.5 \mu \mathrm{m}, 5.5 \mu \mathrm{m}, 6.5 \mu \mathrm{m}$ and $7.5 \mu \mathrm{m})$ of MPE were studied in the magnetophoresis on a microscopic scale. Magnetophoresis model would be used for calculation of the number of IONP deposited on the emulsion droplet of MPE by the experimental data in Chapter 4.

For diameter, $D$ of $2.5 \mu \mathrm{m}$ of emulsion droplet of MPE,

$$
\begin{gathered}
F_{\text {mag }}=F_{d r a g} \\
m_{p} M_{p} \nabla B=6 \pi \eta R v_{T}
\end{gathered}
$$

Viscosity of diluted MPE, $\eta=0.001$ Pa s or $0.001 \mathrm{~kg} \mathrm{~s}^{-2} \mathrm{~A}^{-1} \mathrm{~m}^{-1}$

Terminal velocity of emulsion droplets, $v_{T}=3.07 \times 10^{-6} \mathrm{~m} \mathrm{~s}^{-1}$

Radius of emulsion droplet of MPE, $R=0.5 \times D=1.25 \times 10^{-6} \mathrm{~m}$

(Mass) magnetization of IONP, $M_{p}=38.67 \mathrm{emu} / \mathrm{g}$ or $38.67 \mathrm{Am}^{2} / \mathrm{kg}$

Magnetic flux density gradient, $\nabla B$ at $0.2 \mathrm{~cm}=12.95 \mathrm{~T} / \mathrm{m}$ or $12.95 \mathrm{~kg} \mathrm{~s}^{-2} \mathrm{~A}^{-1} \mathrm{~m}^{-1}$

Density of IONP $=5200 \mathrm{~kg} \mathrm{~m}^{-3}$

Average of radius of IONPs in the IONPs-PSS-CTAB from TEM results, $r=3.56 \mathrm{~nm}$ or $3.56 \times 10^{-9} \mathrm{~m}$ 
$m_{p}=\frac{6 \pi\left(0.001 \mathrm{~kg} \mathrm{~m}^{-1} \mathrm{~s}^{-1}\right)\left(1.25 \times 10^{-6} \mathrm{~m}\right)\left(3.07 \times 10^{-6} \mathrm{~ms}^{-1}\right)}{\left(38.67 \mathrm{Am}^{2} \mathrm{~kg}^{-1}\right)\left(12.95 \mathrm{kgs}^{-2} \mathrm{~A}^{-1} \mathrm{~m}^{-1}\right)}$

Total mass of IONPs deposited on MPE, $m_{p}=1.44 \times 10^{-16} \mathrm{~kg}$

Surface area of MPE

$=4 \pi r^{2}$

$=4 \pi\left(1.25 \times 10^{-6} \mathrm{~m}\right)^{2}$

$=1.963 \times 10^{-11} \mathrm{~m}^{2}$

Maximum packing factor of IONPs on the MPE droplet $=0.74$

Total surface area of MPE available for IONPs occupation

$=($ Surface area of MPE) $\mathrm{x}$ (Maximum packing factor of IONPs on MPE)

$=\left(1.963 \times 10^{-11} \mathrm{~m}^{2}\right) \times(0.74)$

$=1.453 \times 10^{-11} \mathrm{~m}^{2}$

Area occupied by one IONP

$=\pi r^{2}$

$=\pi\left(3.56 \times 10^{-9} \mathrm{~m}\right)^{2}$

$=3.982 \times 10^{-17} \mathrm{~m}^{2} /$ nanoparticle

Number of IONPs required to form full monolayer on MPE

$=\frac{\text { Total surface area of MPE available for IONP occupation }}{\text { Area occupied by one IONP }}$ 


$$
\begin{aligned}
& =\frac{1.453 \times 10^{-11} \mathrm{~m}^{2}}{3.982 \times 10^{-17} \mathrm{~m}^{2} / \text { nanoparticle }} \\
& =364932 \text { nanoparticles } \\
& \text { Volume of one IONP } \\
& =\frac{4}{3} \pi r^{3} \\
& =\frac{4}{3} \pi\left(3.56 \times 10^{-9}\right)^{3} \\
& =1.890 \times 10^{-25} \mathrm{~m}^{3} \\
& \text { Mass of one IONP } \\
& =(\text { Volume of one IONP) } \times(\text { Density of IONP) } \\
& ==1.89 \times 10^{-25} \mathrm{~m}^{3} \times 5200 \mathrm{~kg} \mathrm{~m} \mathrm{~m}^{-3} \\
& =9.83 \times 10^{-22} \mathrm{~kg} / \text { nanoparticle }
\end{aligned}
$$

Number of IONP deposited on MPE

$$
\begin{aligned}
& =\frac{\text { Total mass of IONP deposited on MPE }}{\text { Mass of one IONP }} \\
& =\frac{1.44 \times 10^{-16} \mathrm{~kg}}{9.83 \times 10^{-22} \mathrm{~kg} / \text { nanoparticle }} \\
& =147036 \text { nanoparticles }<364892 \text { nanoparticles }
\end{aligned}
$$

Fraction of number of IONPs deposited on the emulsion droplet of MPE

$$
=\frac{\text { Number of IONPs deposited on MPE }}{\text { Number of IONPs available to be deposited on MPE }}
$$


$=\frac{147036}{364892}$

$=0.4029$

Percent coverage \% of IONPs on the emulsion droplet

$=0.4029 \times 100$

$=40.29 \%$ coverage

Packing density of IONPs on MPE

$=\frac{\text { Number of IONPs deposited on the emulsion droplet of MPE }}{\text { Surface area of MPE }}$

$=\frac{147036}{1.963 \times 10^{-11} \mathrm{~m}^{2}}$

$=7.49 \times 10^{15}$ nanoparticles $/ \mathrm{m}^{2}$

The calculation steps are repeated for the other five diameters of emulsion droplets which are 3.5 $\mu \mathrm{m}, 4.5 \mu \mathrm{m}, 5.5 \mu \mathrm{m}, 6.5 \mu \mathrm{m}$ and $7.5 \mu \mathrm{m}$. All the values of the number of IONPs required to form a full monolayer on the emulsion droplet, number of IONPs deposited on the emulsion droplet, packing density of IONPs on the emulsion droplet and the percent of coverage of IONPs were shown in Table 1. 